ARTÍCULO ORIGINAL

\title{
Pena de morte nas páginas do The New York Times. Um estudo sobre a relação entre punição capital, eleições e opinião pública
}

\author{
Death penalty in the pages of The New York Times. A study on the relationship \\ between capital punishment, elections and public opinion
}

Thiago Perez Bernardes de Moraes ${ }^{1}$

\begin{abstract}
Resumo: A pena de morte tem sido um dos temas mais polêmicos nos meios de comunicação nos Estados Unidos. Nesse sentido, propomos que em alguma medida, o enquadramento midiático pode exercer efeito sobre a opinião pública (oque não é uma idéia nova na literatura), em uma perspectiva de cascata o onde há fluxos que se desenvolvem de forma interdependentes. Esse trabalho visa responder duas questões: a) o enquadramento do tema pena de morte, em perspectiva temporal, guarda relação com o enquadramento do tema eleições? A publicação de matérias sobre punição capital afeta o apoio público á pena de morte? Para responder essas perguntas traçamos duas hipóteses: a) existe uma relação histórica entre o enquadramento de eleições e o do tema pena de morte; b) quanto maior o volume de publicações, maior é o apoio público em favor da pena de morte. Nossos resultados mostram relativa aderência de nossas hipóteses: a) 54\% do enquadramento anual de matérias sobre pena de morte podem ser explicados pelo enquadramento do jornal para materiais sobre eleições; b) 24\% da queda da desfavoralidade e 38\% do aumento da favoralidade histórica dos americanos em relação a pena de morte podem ser explicados por conta do volume de publicação anual de matérias sobre pena de morte no The New York Times.
\end{abstract}

Palavras-chave: The New York Times, Pena de Morte, Eleições, Opinião Pública, Chronicle.

Abstract: The death penalty has been one of the most controversial themes in the media in the United States. Accordingly we propose that to some extent, the media framework can exercise effect on public opinion (what is not a new idea in the literature), in a perspective of the waterfall where there are streams that develop interdependent way. This research aims to answer two questions: a) the framing of the topic of the death penalty, in temporal perspective, save relationship with framing the election theme? The publication of articles about capital punishment affects the public will support the death penalty? To answer these questions, we make two assumptions: a) there is a history between the election and the framework of the theme of the death penalty; (b)) the higher the volume of publications, the greater is the public support in favor of the death penalty. Our results show on adhesion of odds: 54\% of annual framework) of articles about the death penalty can be explained by the framework paper for materials about elections; b) $24 \%$ of fall of desfavoralidade and $38 \%$ of the increased favoralidade of Americans regarding the death penalty can be explained due to the volume of annual publication of articles about the death penalty in The New York Times.

Keywords: The New York Times, death penalty, elections, public opinion, Chronicle.

1 Universidad Argentina John Fitzgerald Kennedy, Centro Universitário Campos de Andrade. Brasil. (thiagomoraessp@hotmail.com)

Recibido: 28/07/2015; Aceptado: 12/11/2015. http://dx.doi.org/10.18004/riics.2015.diciembre.223-240 


\section{INTRODUÇÃO}

Os Estados Unidos detêm o maior sistema carcerário do mundo e é uma das poucas democracias que ainda faz uso da pena capital. Neste diapasão, nossa investigação debruça-se sobre a relação entre ciclos eleitorais, meios de comunicação e apoio público em relação á pena de morte. Uma das justificativas deste trabalho reside no fato de que qualquer movimento para reduzir as taxas de encarceramento deve ad hoc ser lastreado por uma análise clara do papel que a política, a mídia, as etnias e a formação de coalizações políticas que leva a sucessos no campo legislativo (Mauer, 2001). Outra justificativa reside no fato de que, apesar de ser amplamente estudado, o tema pena de morte, carece de estudos estatísticos que exploram de forma isolada potenciais forças sociais e políticas que podem afetar a opinião pública sobre pena de morte (Jacobs \& Carmichael, 2002, Moraes, 2015).

Esse trabalho tem o objetivo de responder duas questões: a) o enquadramento do tema pena de morte, em perspectiva temporal, guarda relação com o enquadramento do tema eleições? A publicação de matérias sobre punição capital afeta o apoio público á pena de morte? Para responder essas perguntas traçamos duas hipóteses: a) existe uma relação histórica entre o enquadramento de eleições e o do tema pena de morte; b) quanto maior o volume de publicações, maior é o apoio público em favor da pena de morte.

A pena de morte na Lei dos Estados Unidos ocupa um papel único na ciência e no direito social. Apesar de ela de fato, afetar um número relativamente pequeno de indivíduos, é um dos aspectos mais estudados do sistema de justiça criminal. Existe uma série de razões para que exista esse elevado nivel de interesse acadêmico pelo tema, nisso está incluso o fato de que, está em jogo nos casos de pena de morte em última instância a vida de indivíduos (que podem ser inocentes). É possivel dizer que a pena de morte difere-se de todas as demais formas de punição criminal, isso considerando que ela é a única totalmente irrevogável. Ela também é única na rejeição da reabilitação do condenado como um objetivo básico de qualquer sistema de justiça criminal (Levinson, Smith \& Young, 2014; Haney, Weill, Lynch \& Cutler, 2015). Devemos considerar que o sistema judicial pode (e comete) erros, no caso da pena capital, é impossivel se obter uma reparação justa quando um inocente é executado. Neste diapasão, as pesquisas em psicologia social indicam que o sistema legal americano pode cometer erros por varias razões: a) os júris depositam grande fé nos depoimentos de testemunhas, entretanto, por via de regra esses depoimentos quase sempre contem erros e são dissonantes da 
realidade; b) ainda no que diz respeito ao peso das testemunhas, é muito dificil distinguir se uma testemunha falta com a verdade, mesmo empregando detectores de mentira; c) juris são grupos de individuos que buscam chagar a decisões unânimes e consensuais através de uma negociação baseada em troca de informações e argumentos, nesse processo, devemos ter em conta que uma série de pressões para a conformidade e de processos grupais podem levar a decisões falhas (Aronson, Wilson \& Akert, 2002).

A primeira vez que a pena de morte foi aplicada nos Estados Unidos foi em 1608, com a execução de um capitão de nome George Kendall, que foi morto por um pelotão de fuzilamento, acusado de ser um espião do governo espanhol. Podemos dizer que a pena de morte como punição para crimes foi uma herança trazida junto com os primeiros colonizadores europeus britânicos. Isso se considerarmos que a Grã-Bretanha, lar dos colonizadores dos Estados Unidos, aplicava pena de morte de forma habitual desde o século X. Em 1612, Sir Thomas Dale, governador da provincia da Virginia ao outorgar as Leis Marciais, forneceu lastro para que a pena de morte fosse aplicada, mesmo em casos de delitos menores como realizar negociações com índios, matar um animal ou roubar frutas. De 1608 até 2011, 15.625 pessoas foram executadas nos Estados Unidos, sendo que a maioria era negra (7.353) (Moraes, 2015).

Em 1972, em um dos momentos da historia americana em que a pena de morte registrou um dos menores níveis apoio publico já mensurados, o Supremo Tribunal Federal no caso Furman Versus Georgia, decidiu que a pena de morte viola a oitava Emenda da Constituição dos Estados Unidos no que diz respeito à probidade de punição cruel e incomum. Por conta disso, a pena de morte e as execuções foram suspensas temporariamente (Falco \& Freiburguer, 2011). Após esse período, o estado da Flórida e mais 34 estados passaram a promulgar novas leis relacionadas à pena de morte e em 1976 estes estatutos foram aprovados pelo Supremo Tribunal Federal. Essa decisão considerou também que a pena de morte não infringia a oitava emenda da constituição. A pena capital voltou a ser aplicada, entretanto, houve mudanças nos métodos aplicados. Quase 90 anos depois da cadeira elétrica (1890), após muita pressão, a injeção letal tornou-se atualmente o método mais popular utilizado nos Estados Unidos, nesse sentido, câmaras de gás, enforcamento, fuzilamento e cadeiras elétricas começaram a ser vistos como métodos antiquados e arriscados. Desde o inicio de 2000, 98\% das execuções nos Estados Unidos foram por meio da injeção letal. Em nível local, atualmente a pena de morte nos Estados Unidos é considerada legal em 33 estados e é proibida nos demais 18 estados (Moraes, 2015). 
Em nivel Federal em 1994 o presidente Bill Clinton assinou o Violent Crime Control and Law Enforcement Act que expandiu a pena de morte federal para cerca de 60 crimes, alguns dos quais não envolvem homicídios. Em 1996, em resposta ao atentado de Oklahoma, Bill Clinton assinou o Anti-Terrorism and Effective Death Penalty Act, um ato que afetou tanto os presos estaduais como federais, restringindo a avaliação em tribunais federais estabelecendo prazos mais curtos para a execução, limitando a oportunidade de audiências probatórias e permitindo apenas a apresentação de um único habeas corpus no tribunal federal. Os defensores da pena de morte afirmam que esta mudança no texto constitucional acelera os processos judiciais e reduz de forma drástica à custa dos processos. Entretanto, os críticos temem que uma avaliação mais rápida por parte de tribunais federais aumenta o risco de que inocentes sejam executados (Rannik, 1996; Pearson, 1998; Windlesham \& Windlesham, 1998).

Teóricos da democracia observam correlações significativas entre a opinião pública e a política governamental, entretanto é dificil determinar a direção dessa causalidade. A influência sobre o governo pode ser mais forte quando funcionários e ou proprietários dos meios de comunicação compartilham e interesses e valores. A ordem temporal levanta implicações parta a relação entre política e opinião pública: os formuladores de políticas públicas podem selecionar novas políticas e depois mover a opinião pública a fim de ganhar apoio para a sustentação das mudanças políticas previstas (Chomsky, 2000; Moraes, Santos \& Torrecillas, 2014).

Em tempos recentes, sobretudo na última década, tem florescido uma literatura que tem buscado correlacionar a crescente divisão entre os Estados Unidos e outras democracias liberais do Ocidente no que diz respeito às praticas de punição penal. Podemos dizer que com os aumentos acentuados das taxas de crime, com o surgimento de uma sofisticada rede de trafico de drogas internacional e também porás ameaças de terrorismo, levaram os Estados Unidos a experimentar uma revolução no sistema de justiça criminal á partir de 1960 (Garland, 2013).

Nesse sentido, o crescimento sem precedentes da população carcerária estadunidense, pode ser atribuído a um complexo arcabouço de evoluções na política e na pratica das sentenças. O aumento da criminalidade na década de 1960 veio em um momento de grande ebulição social, com uma crescente onda de divisões sociais e politicas do crime em nível nacional. Estas circunstâncias coincidiram no tempo e influenciou o debate sobre as práticas de condenações, o que em última instância, culminou em uma dramática mudança no modelo 
dominante de prática de sentenças que vigorou na maior parte do século $\mathrm{XX}$ (Mauer, 2001; Moraes, 2015).

Alguns epifenômenos dessa revolução são: a) iniciativa de "tolerância zero"; b) expansão do âmbito de aplicação do direito penal substantivo; c) "três tentativas" de se formar um estatuto aumentando a punição para reincidentes; d) aumento do uso de sanções penais para jovens delinquentes; e) autorização generalizada para realização de execuções; f) supressão do direito de liberdade condicional e h) a crescente utilização da pena de morte (Garland, 2013; Cole, Smith \& DeJong, 2015). Em 1972, para cada 100.000 adultos nos estados Unidos, 93 indivíduos foram presos em uma prisão, Estadual ou Federal; em 2007, o número subiu para 506 indivíduos. Nesse ponto, a taxa de encarceramento praticada nos Estados Unidos é muito superior a de qualquer outro país do mundo (Moraes, 2013, 2014; Enns, 2014; Sudbury, 2014).

Sobre a pena de morte e opinião pública podemos dizer que, além das razões mencionadas, a opinião pública também tem sido um pivô como determinante da taxa de encarceramento desde pelo menos 1953. Nesse ponto, podemos dizer que o apoio público dos americanos á um maior rigor nas punições criminais formaram uma corrente onde os grupos de interesse e formuladores de políticas têm avançado em politicas que conduziram os Estados Unidos a se tornar o país mais punitivo do mundo (Enns, 2014). Em 1966, o sentimento estadunidense pró-pena de morte teve seu menor índice, $42 \%$ da população, entretanto, 20 anos depois, o indice subiu de forma constante alcançando mais de $71 \%$ da população adulta. Os principais de terminantes desse apoio parecem em parte residir nas inclinações políticas, etnias, sexo, e status sócio econômico. Entretanto, o sentimento pró-pena de morte não se distribui de forma uniforme, por exemplo, cerca de $1 / 3$ dos que apoiam a pena de morte nos Estados unidos, estão dispostos a desistir dessa posição se for proposto como alternativa a prisão perpetua sem direito a liberdade condicional. Em última instância, podemos propor que o sentimento em relação a pena de morte, e a formação de atitudes, não são determinados por uma racionalidade utilitária (como a proposta pelos conceitos da teoria da escolha racional), mas antes disso, o que se destaca são os valores morais que exercem influência em todas as esferas da vida, e também demarca as linhas divisórias entre liberais e conservadores (Zeisel \& Gallup, 1989; Moraes, 2015).

Entendemos que os decisores politicos respondem mais diretamente aos valores públicos relacionados à moralidade do que políticas não relacionadas com este campo. Entretanto, há de se considerar que o nível e a estrutura da resposta 
são diferentes quando essa política que envolve moralidade é largamente apoiada por uma maioria (um "consenso" politico e social) do que quando a opinião pública é majoritariamente contrária e ou está dividida. A evidência empírica indica que a opinião pública está intimamente relacionada a divisões em questões políticas, onde os decisores políticos dão mais atenção a estes pontos, em revelia de outros (Enns, 2014; Moraes, 2015). Quando a opinião pública é unilateral, a ideologia política da elite exerce quase que exclusiva influência sobre o cenário e a execução da mudança política e legislativa.

As principais mudanças ocorreram na forma de restrições severas sobre juízes e oficiais de liberdade condicional, muitas jurisdições e uma drástica diminuição do peso que os exames das circunstâncias iniciais do ofensor e do crime poderiam exercer. Essas mudanças, somadas ao impacto da guerra contra as drogas tem contribuído para um exponencial aumento da taxa de encarceramento, á partir, sobretudo de 1980. As taxas de encarceramento, o uso ou não da pena de morte e a adoção ou não de sentenças mais brandas exigem estudos interdisciplinares, considerando que são objetos de estudo multicausais (Mauer, 2001; Hood \& Hoyle, 2014; Cole, Smith \& DeJong, 2015), nesse ponto, esse trabalho visa preencher a lacuna referente à construção de realidade referente à pena de morte por parte da mídia.

Estudos empíricos sobre a cobertura midiática de campanhas eleitorais apontam que, nos Estados unidos, a forma com que as agendas políticas são formadas e, sobretudo a forma com que o discurso político é exposto varia de forma mais ou menos consistente de estado para estado, e também, em cada um dos meios de comunicação utilizados, como televisão e jornal, por exemplo (Ridout \& Mellen, 2007; Moraes \& Santos, 2015).

Ao que parece, existe uma tendência onde alguns tipos de democracias são mais susceptiveis a acabar com o uso da pena capital do que outras. Um ponto importante reside na forma com que a democracia é produzida e conduzida. Sistemas parlamentares com representação proporcional (democracia consensual, na leitura de Lijphart) são mais propensos a acabar com o uso da pena de morte. Além disso, a análise empírica de 1960 a 2005 em 150 países indica também que: 1) transições democráticas podem aumentar a probabilidade de abolição da pena de morte; 2) os incentivos fornecidos por organizações internacionais, sobretudo na Europa, têm levado alguns países à adoção do rumo da abolição (Mc Gann \& Sandholtz, 2012). 
Há de se considerar que o tema pena de morte é, no mínimo, muito sensível e boa parte das vezes ligada a um contexto que pode ser usado pela mídia para gerar narrativas assustadoras. Nesse sentido, há de se considerar que comunicações que despertam medo podem, em larga medida, causar grande influência estrutural na personalidade e no modus operandi da tomada de atitude (Aronson, Wilson \& Akert, 2002).

Para esse trabalho, há de se considerar também os preceitos do "Método Yale de Mudança de Atitude", onde no limite se outorga que o escopo de possibilidade de persuasão reside no poder de persuasão do comunicador, na fonte de mensagem e em aspectos de audiência. Nesse método são contabilizados pelo menos três escopos distintos: a) a fonte da comunicação; b) a natureza da comunicação; c) a natureza da audiência. (Aronson, Wilson \& Akert, 2002). Galbraith ao analisar o papel dos jornais na sociedade percebe que ele é como um intermediário, um condutor. Por exemplo, a ciência produz teorias sociais, como o darwinismo social ou a economia neoclássica e a mídia torna essas doutrinas inteligiveis para uma grande parcela da população. A posteriori processos políticos podem se ancorar (neste e em outro discurso) já legitimado pelo jornal, e tal discurso por sua vez tem capacidade de gerar lastro para ações políticas e legislativas (Moraes \& Maia, 2014; Moraes \& Torrecillas, 2014).

Considerando que o The New York Times é historicamente um dos jornais mais vendidos e lidos entre os estadunidenses, há de se considerar que em larga medida este meio de comunicação goza de capital social e de larga credibilidade.

Há também de considerarmos os argumentos do "Modelo de Probabilidade de Elaboração", onde o pivô, por assim dizer da persuasão, é à força dos argumentos e pequenos aspectos superficiais da comunicação. Há de se considerar também que as emoções influenciam de forma direta na formação das atitudes de formas diversas (Aronson, Wilson \& Akert, 2002).

O The New York Times foi fundado em setembro de 1851. Basicamente, é um jornal muito popular, de circulação diária, publicado na cidade de Nova Iorque e distribuído nos Estados Unidos. Atualmente o The New York Times pertence a um grande conglomerado que controla 17 jornais e cinquenta sites de notícias (Usher, 2014).

Politicamente falando, a evidência empírica permite dizer que na maior parte da vida histórica do jornal, há uma tendência de em alguma medida favorecer a 
imagem do Partido Democrata. Por exemplo, em períodos onde houve presidentes republicanos, o The New York Times deu mais ênfase a temas onde os democratas são percebidos como mais competentes (saúde, política de emprego, bem estar social e os direitos civis). Ao que parece é sustentável a hipótese de que o The New York Times é lastreado por um partidarismo pró Democrata, que fica latente, sobretudo em períodos de campanhas presidenciais, onde o jornal da mais ênfase para assuntos no qual os republicanos são considerados "fracos" em gerar respostas (Puglisi, 2011; Larcinese, Puglisi \& Snyder, 2011).

Um estudo interessante sobre o papel dos meios de comunicação na formação das atitudes em relação a pena de morte investigou possiveis correlações e efeitos dentro da música popular. Para isso o estudo utilizou um agregado de dados de opinião acerca da pena de morte (dados temporais, para se aferir o impacto das mudanças), canções sobre pena de morte. Os resultados demonstram que a consciência pública sobre a pena de morte, e também, as mudanças na opinião pública acerca da pena de morte, é resultado de um agregado de variáveis independentes que são associados ao conteúdo dos meios de comunicação de massa. No caso das canções sobre pena de morte, identificou-se que em um ano onde cresce o número de músicas sobre pena de morte, há uma tendência de que durante dois anos o apoio público á pena de morte sofra significativa queda (Bohm $\&$ Surette, 2013).

Nesse sentido, nossa hipótese é que, o tema pena de morte receba maior abrangência em períodos eleitorais, pois em larga medida, esse é um dos pontos mais sensiveis da agenda política. Assim, podemos dizer que essa relação histórica que se concebe nos Estados Unidos entre o trema pena e morte e eleições, fora historicamente construída pelas estruturas socais. Podemos dizer que o comportamento do The New York Times é tanto causa como consequência, nossos resultados assim exploram um dos muitos epifenômenos dessa construção social. Neste diapasão, o objetivo principal do nosso trabalho é aferir se há uma relação causal entre as publicações no The New York Times sobre pena de morte e a opinião pública dos estadunidenses sobre este tema.

\section{METODOLOGIA}

Nesse trabalho utilizamos uma ferramenta Chronicle (NYTlabs), Para criar frequências temporais de publicações para matérias relacionadas a eleições e pena de morte de 1851 até 2015, totalizando, 164 anos de dados para análise. Basicamente, a ferramenta Chronicle serve para monitorar as mudanças e o uso de 
linguagem e temas na cobertura do The New York Times ao longo da historia. A ferramenta funciona de forma parecida ao Google Ngram Viewer, mas ao invés de gerar dados sobre publicações em livros, ela gera dados relativos apenas às publicações do The New York Times. Para qualquer palavra ou frase, a ferramenta traça uma métrica temporal de 1851 até o presente e as entradas de dados são classificadas por anos.

Traçada as duas métricas com o Chronicle relativas às publicações no The New York Times, cruzamos os dados destas frequências. Nos também utilizamos dados do Gallup Institute referente a pesquisas de opinião sobre o apoio publico em relação a pena de morte nos Estados Unidos á partir de1936 até 2014. Realizamos comparações entre a freqüência de publicação de matérias sobre de morte no The New York Times e a favoralidade e desfavoralidade de opiniões em relação a pena de morte. Utilizamos para lidar com os dados o software SPSS 21.0 (Statistical Package for the Social Sciences) com o qual geramos estatisticas descritivas, correlações utilizando o índice de Pearson e regressões lineares. Para todos os casos consideramos um intervalo de confiança de $95 \%$.

\section{RESULTADOS}

No Gráfico 1 traçamos tendências históricas anuais de 1851 até 2015 de publicações no The New York Times de matérias que continham os termos pena de morte (eixo secundário) e eleições (eixo principal).

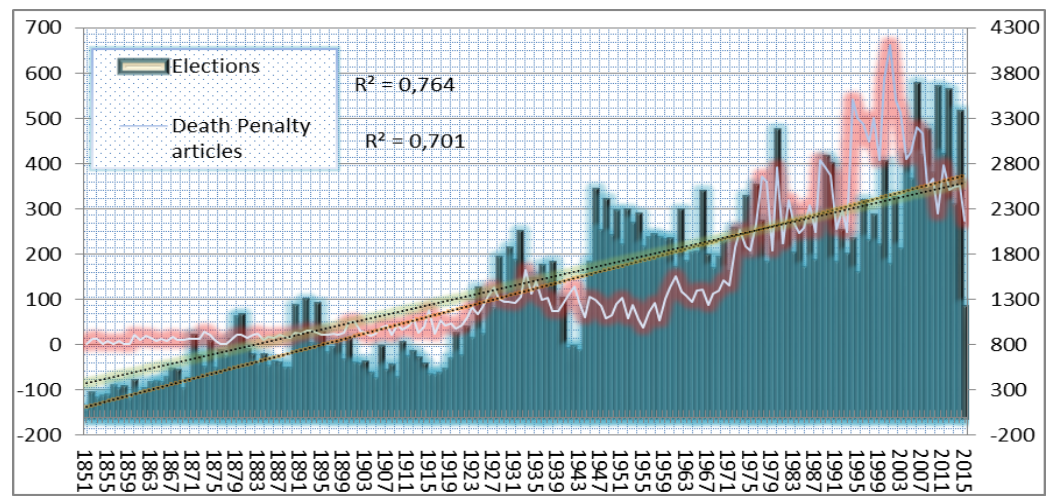

Gráfico 1. Publicações relativas a eleições e a pena de morte no The New York Times de 1851 até 2015. Fonte: Chronicle, elaboração do autor. 
É visível na estatística descritiva (tabela 1) que a media de publicações no jornal de materiais sobre eleições é muito superior a media de publicações de tema de morte, isso fica evidenciado, sobretudo ao observarmos os valores máximos e a soma total.

Tabela 1. Estatística descritiva das publicações relativas a eleições e pena de morte no The New York Times de 1981 até 1985.

\begin{tabular}{l|l|l}
\hline & $\begin{array}{c}\text { Pena_de_Morte_New_- } \\
\text { York_Times }\end{array}$ & \multicolumn{1}{|c}{ Eleições } \\
\hline $\mathrm{N} \quad$ Válido & 165 & 165 \\
Média Ausente & 0 & 0 \\
Modelo padrão & 135,4364 & 1393,5515 \\
Variância & 153,82427 & 850,06379 \\
Amplitude & 23661,906 & 722608,444 \\
Minimo & 661,00 & 3595,00 \\
Máximo & 1,00 & 81,00 \\
Soma & 662,00 & 3676,00 \\
\hline
\end{tabular}

Fonte: elaboração do autor.

Evidencia-se (Tabela 2, Gráfico 2) a existência de uma significativa correlação positiva entre a frequência de publicações anuais de matérias no jornal relativas a eleições e pena de morte.

Tabela 2. Correlação entre publicações relativas a eleições e a pena de morte no The New York Times de 1851 até 2015.

\begin{tabular}{ll|r|r}
\hline & & $\begin{array}{c}\text { Pena_de_Morte_New } \\
\text { York_Times }\end{array}$ & eleições \\
& Correlação de Pearson & 1 &, $740^{* *}$ \\
Pena_de_Morte_N & Sig. (2 extremidades) &, 000 \\
ew_York_Times & produtos cruzados & 3880552,582 & 15876501,291 \\
& Covariância & 23661,906 & 96807,935 \\
& N & 165 & 165 \\
& Correlação de Pearson &, $740^{* *}$ & 1 \\
eleições & Sig. (2 extremidades) &, 000 & 1 \\
& Soma dos quadrados e & 15876501,291 & 118507784,81 \\
& produtos cruzados & 96807,935 & 722608,444 \\
Covariância & 165 & 165 \\
\hline
\end{tabular}

*^A correlação é significativa no nível 0,01 (2 extremidades). Fonte: elaboração do autor. 


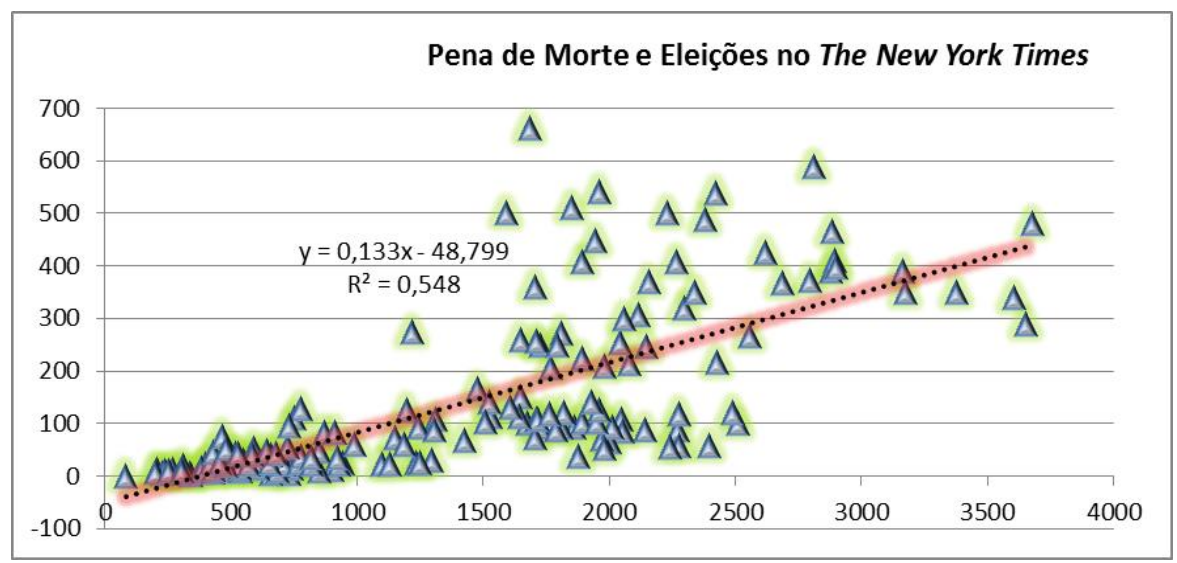

Gráfico 2. Dispersão entre publicações relativas a eleições e a pena de morte no The New York Times de 1851 até 2015. Fonte: elaboração do autor.

A seguir traçamos uma regressão linear (Tabela 3) considerando como variável dependente o volume de publicações relativa à pena de morte e como variável independente as publicações sobre eleições.

Tabela 3. Regressão Linear entre a variável dependente publicações relativas a pena de morte no The New York Times e a variável independente publicações sobre eleições.

\begin{tabular}{|c|c|c|c|c|c|c|}
\hline Modelo & & $\mathbf{R}$ & $\begin{array}{c}\mathbf{R} \\
\text { quadrado }\end{array}$ & $\begin{array}{c}\text { R quadrado } \\
\text { ajustado }\end{array}$ & \multicolumn{2}{|c|}{$\begin{array}{l}\text { Erro padrão da } \\
\text { estimativa }\end{array}$} \\
\hline 1 & &, $740^{a}$ &, 548 &, 545 & \multicolumn{2}{|c|}{103,72143} \\
\hline Modelo & & \begin{tabular}{|l|} 
Soma dos \\
Quadrados
\end{tabular} & $\mathrm{df}$ & $\begin{array}{l}\text { Quadrado } \\
\text { Médio }\end{array}$ & $\mathrm{F}$ & Sig. \\
\hline & Regressão & 2126976,668 & 1 & 2126976,668 & \multirow[t]{3}{*}{197,709} & \multirow[t]{3}{*}{, $000^{\mathrm{b}}$} \\
\hline \multirow[t]{2}{*}{1} & Resíduos & 1753575,914 & 163 & 10758,134 & & \\
\hline & Total & 3880552,582 & 164 & & & \\
\hline \multirow{2}{*}{\multicolumn{2}{|c|}{ Modelo }} & \multicolumn{2}{|c|}{$\begin{array}{l}\text { Coeficientes não } \\
\text { padronizados }\end{array}$} & $\begin{array}{l}\text { Coeficientes } \\
\text { padronizados }\end{array}$ & \multirow[t]{2}{*}{$\mathrm{t}$} & \multirow[t]{2}{*}{ Sig. } \\
\hline & & B & $\begin{array}{l}\text { Modelo } \\
\text { padrão }\end{array}$ & Beta & & \\
\hline \multirow{2}{*}{1} & (Constante) & $-51,258$ & 15,540 & & $-3,298$ & ,001 \\
\hline & Eleições &, 134 & ,010 & ,740 & 14,061 & ,000 \\
\hline
\end{tabular}

a. Preditores: (Constante), Eleições. b. Variável dependente: Pena_de_Morte_New_York_Times. Fonte: Elaboração do autor. 
Na Tabela 3 verifica-se que obtivemos um r quadrado ajustado de 545, o que indica que $54 \%$ do enquadramento anual do tema pena de morte pode ser explicado pelo enquadramento do tema eleições. Em alguma medida podemos dizer que anos onde há mais publicações sobre eleições (anos eleitorais) são também os anos onde o jornal busca "aumentar a chama" do debate fazendo um maior número de matérias sobre pena de morte. A validade da regressão se confirma no valor de significância global obtido no ANOVA, no valor do coeficiente padronizado beta e na significação de $t$.

\section{Efeito na opinião pública}

No Gráfico 3 traçamos as frequências relativas a publicações de materiais sobre pena de morte no The New York Times e a evolução do apoio público a pena capital, no período de 1936 até 2014. Consideramos apenas as frequências de publicação no jornal para anos em que houve inquéritos de opinião e em anos em houveram mais de um inquérito consideramos uma média relativa a todos eles.

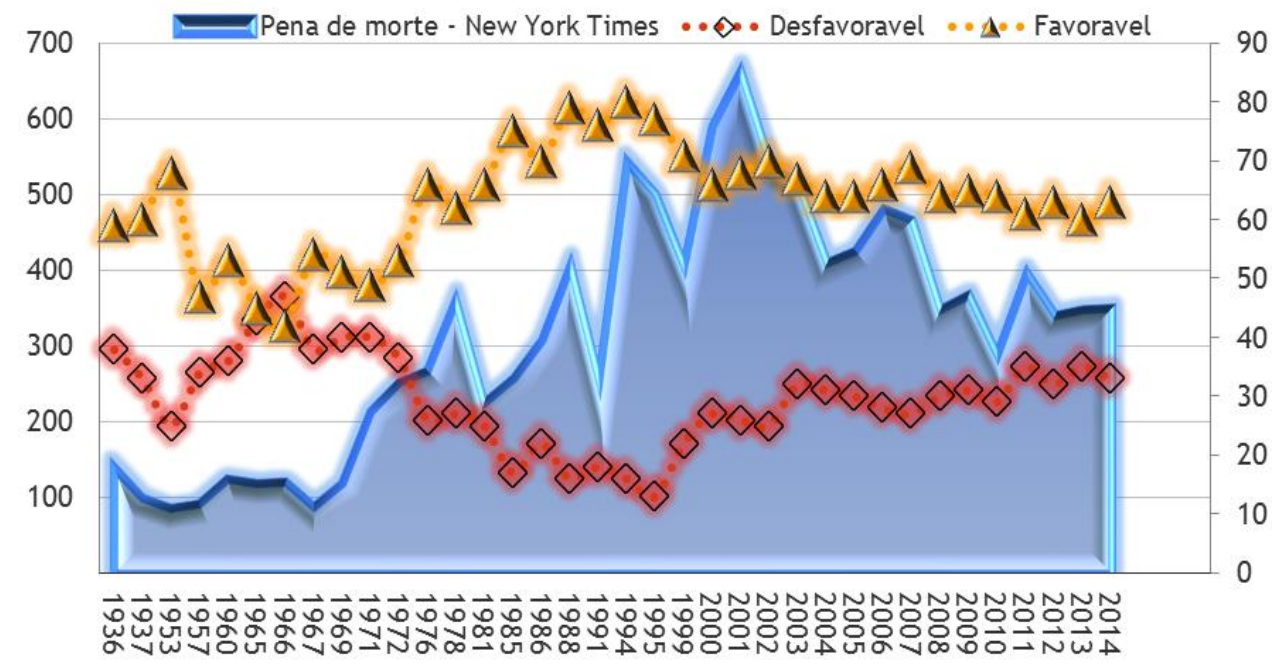

Gráfico 3. Evolução de publicações no The New York Times de matérias sobre pena de morte e o apoio público em relação a pena capital. Fonte: Chronicle, Gallup Institute, elaboração do autor.

Para melhor estudar o efeito que as matérias do The New York Times sobre pena de morte pode exercer sobre a opinião publica dos estadunidenses traçamos na Tabela 4 correlações utilizando o índice de Pearson. 
Tabela 4. Correlações entre publicações no The New York Times de matérias sobre pena de morte e o apoio público em relação a pena capital.

\begin{tabular}{|c|c|c|c|c|}
\hline & & Favorável & Desfavorável & $\begin{array}{c}\text { Pena_de_Mort } \\
\text { e_New_York_T } \\
\text { imes }\end{array}$ \\
\hline \multirow{5}{*}{ Favorável } & Correlação de Pearson & 1 &,$- 938^{* *}$ &, $630^{* *}$ \\
\hline & Sig. (2 extremidades) & & ,000 & ,000 \\
\hline & $\begin{array}{l}\text { Soma dos quadrados e } \\
\text { produtos cruzados }\end{array}$ & 3040,750 & $-2432,875$ & 32681,000 \\
\hline & Covariância & 86,879 & $-69,511$ & 933,743 \\
\hline & $\mathrm{N}$ & 36 & 36 & 36 \\
\hline \multirow{5}{*}{ Desfavorável } & Correlação de Pearson &,$- 938^{* *}$ & 1 &,$- 520^{* *}$ \\
\hline & Sig. (2 extremidades) & ,000 & & ,001 \\
\hline & $\begin{array}{l}\text { Soma dos quadrados e } \\
\text { produtos cruzados }\end{array}$ & $-2432,875$ & 2211,688 & $-22998,500$ \\
\hline & Covariância & $-69,511$ & 63,191 & $-657,100$ \\
\hline & $\mathrm{N}$ & 36 & 36 & 36 \\
\hline \multirow{5}{*}{$\begin{array}{l}\text { Pena_de_Morte_ } \\
\text { New_York_Times }\end{array}$} & Correlação de Pearson & $630^{* *}$ &,$- 520^{* *}$ & 1 \\
\hline & Sig. (2 extremidades) & ,000 & ,001 & \\
\hline & $\begin{array}{l}\text { Soma dos quadrados e } \\
\text { produtos cruzados }\end{array}$ & 32681,000 & $-22998,500$ & 884066,000 \\
\hline & Covariância & 933,743 & $-657,100$ & 25259,029 \\
\hline & $\mathrm{N}$ & 36 & 36 & 36 \\
\hline
\end{tabular}

**. A correlação é significativa no nível 0,01 (2 extremidades). Fonte: elaboração do autor.

Na Tabela 4 e no Gráfico 4 encontramos uma correlação significativa positiva entre o as publicações sobre pena de morte do The New York Times e a favoralidade em relação a pena de morte; encontramos também uma correlação entre as publicações do jornal e a desfavoralidade, mas essa correlação fora negativa. Traçamos nas Tabelas 5 e 6 dois modelos de regressão, sendo que no primeiro a variável dependente é a favoralidade em relação a pena de morte e a independente o volume de publicações no jornal e no segundo mantemos a mesma variável independente, mas trocamos a variável dependente pela desfavoralidade em relação a pena capital. 
Tabela 5. Regressão linear entre a variável dependente favoralidade em relação a pena de morte e a variável independente publicações relativas à pena de morte no The New York Times.

\begin{tabular}{|c|c|c|c|c|c|c|}
\hline \multicolumn{2}{|l|}{ Modelo } & $\mathbf{R}$ & \begin{tabular}{|l|}
$\mathbf{R}$ \\
quadrado \\
\end{tabular} & $\begin{array}{l}\mathbf{R} \quad \text { quadrado } \\
\text { ajustado }\end{array}$ & \multicolumn{2}{|c|}{$\begin{array}{l}\text { Erro padrão da } \\
\text { estimativa }\end{array}$} \\
\hline 1 & & ,630a & ,397 &, 380 & & 7,342 \\
\hline Modelo & & $\begin{array}{c}\text { Soma dos } \\
\text { Quadrados }\end{array}$ & $\mathrm{df}$ & $\begin{array}{c}\text { Quadrado } \\
\text { Médio }\end{array}$ & $\mathrm{F}$ & Sig. \\
\hline \multirow{3}{*}{1} & Regressão & 1208,109 & 1 & 1208,109 & 22,413 &, $000^{\mathrm{b}}$ \\
\hline & Resíduos & 1832,641 & 34 & 53,901 & & \\
\hline & Total & 3040,750 & 35 & & & \\
\hline \multirow[t]{2}{*}{ Modelo } & & \multicolumn{2}{|c|}{ Coeficientes não padronizados } & $\begin{array}{l}\text { Coeficientes } \\
\text { padronizados }\end{array}$ & $\mathrm{t}$ & Sig. \\
\hline & & B & $\begin{array}{l}\text { Modelo } \\
\text { padrão }\end{array}$ & Beta & & \\
\hline \multirow{2}{*}{1} & (Constante) & 51,421 & 2,782 & & 18,482 & ,000 \\
\hline & Favorável &, 037 &, 008 &, 630 & 4,734 & ,000 \\
\hline
\end{tabular}

a. Preditores: (Constante), Pena_de_Morte_New_York_Times_ b. Variável dependente: Favorável. Fonte: Elaboração do autor.

Tabela 6. Regressão Linear entre a variável dependente desfavoralidade em relação a pena de morte e a variável independente publicações sobre pena de morte.

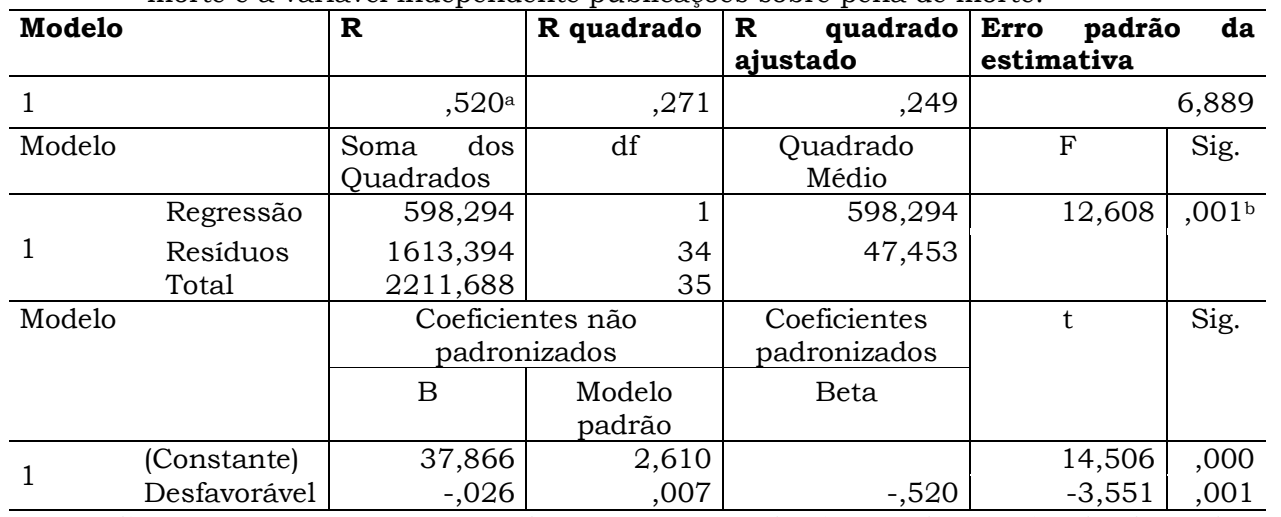

a. Preditores: (Constante), Pena_de_Morte_New_York_Times. b. Variável dependente: Desfavorável. Fonte: Elaboração do autor.

Ambos os modelos são aderentes, vide que apresentam alta significação no ANOVA e também na significação de t. No primeiro modelo encontramos um $r$ quadrado ajustado de ,380 o que significa que 38\% do aumento da favoralidade em relação a pena de morte pode ser explicado pelo volume de publicações sobre pena 
de morte. No segundo modelo encontramos uma relação negativa, com um $r$ quadrado ajustado de 249 , o que indica que $24 \%$ do declinio da desfavoralidade em relação a pena de morte pode ser explicada pela nossa variável independente, o volume de publicações sobre pena de morte no The New York Times.

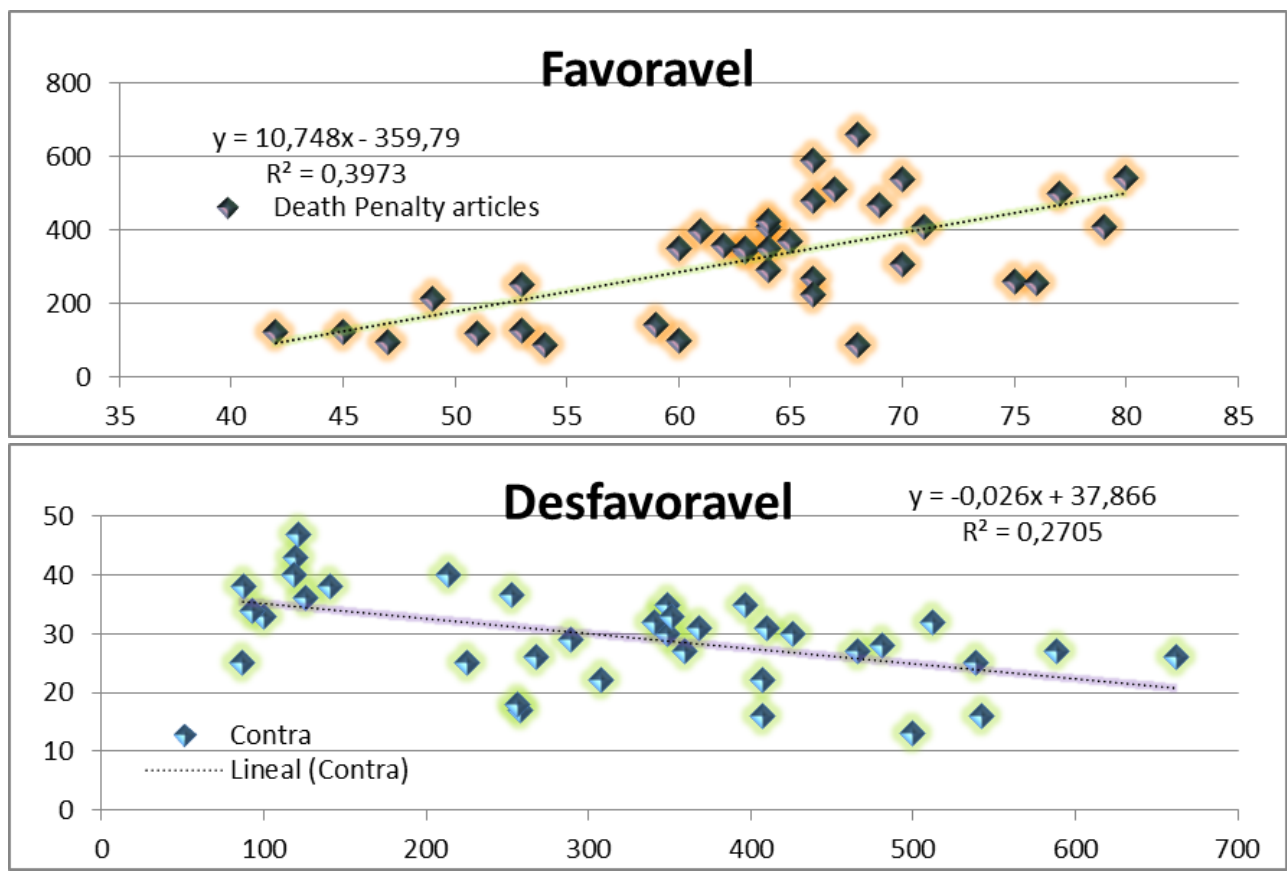

Gráfico 4. Dispersão entre publicações no The New York Times de matérias sobre pena de morte e o apoio público em relação a pena capital.

Como podemos observar nas Tabelas 5 e 6 e também no Gráfico 4, existe um efeito considerável em relação as publicações do The New York Times sobre pena de morte e a opinião pública dos estadunidenses.

\section{CONSIDERAÇÕES FINAIS}

Considerando que a pena de morte é apenas um dos temas da agenda política, nosso estudo não tem a pretensão de ser conclusivo, mas sim exploratório. De toda forma, os resultados mostraram aderência das hipóteses: a) 54\% do enquadramento anual de matérias sobre pena de morte podem ser explicados pelo 
enquadramento do jornal para materiais sobre eleições; b) $24 \%$ da queda da desfavoralidade e $38 \%$ do aumento da favoralidade histórica dos americanos em relação a pena de morte podem ser explicados por conta do volume de publicação anual de matérias sobre pena de morte no The New York Times.

Ao que parece, há uma relação consistente entre o enquadramento de eleições e de pena de morte no jornal, o que reforça a ideia de que o tema pena de morte receba maior atenção em periodos eleitorais, como uma estratégia dos políticos. Nesse diapasão, o enquadramento do jornal seria um epifenômeno dessa relação. O ponto mais interessante parece ser o efeito das publicações sobre a opinião púbica. Em geral, quanto mais publicações do jornal sobre pena de morte, maior é a tendência de desfavoralidade, o que em larga medida sugere que o jornal exerce influência sobre o imaginário popular dos estadunidenses.

\section{REFERÊNCIAS}

Aronson, E., Wilson, T. D., \& Akert, R. M. (2002). Psicologia social em ação 1: Psicologia social e saúde. Psicologia Social, 323-342.

Bohm, R. M., \& Surette, R. (2013). Toward an understanding of aggregate death penalty opinion change: A possible role for popular music. International Journal of Criminology and Sociology, 2, 32-56.

Chomsky, D. (2000). Advance agent of the truman doctrine: The United States, The New York Times, and the Greek Civil War. Political Communication, 17(4), 415-432.

Cole, G., Smith, C., \& DeJong, C. (2015). Criminal justice in America. Cengage Learning.

Enns, P. K. (2014). The public's increasing punitiveness and its influence on mass incarceration in the United States. American Journal of Political Science, 58(4), 857-872.

Falco, D. L., \& Freiburger, T. L. (2011). Public opinion and the death penalty: A qualitative approach. Qualitative Report, 16(3), 830-847.

Haney, C.; Weill, J.; Lynch, M.; \& Cutler, B. (2015). The death penalty: APA handbook of forensic psychology, criminal investigation, adjudication, and sentencing outcomes, In APA handbooks in psychology (vol. 2, pp. 451-510). Washington, DC, US: American Psychological Association.

Hood, R., \& Hoyle, C. (2014). The death penalty: A worldwide perspective. Oxford University Press. 
Jacobs, D., \& Carmichael, J. T. (2002). The political sociology of the death penalty: A pooled time-series analysis. American Sociological Review, 109-131.

Larcinese, V., Puglisi, R., \& Snyder, J. M. (2011). Partisan bias in economic news: Evidence on the agenda-setting behavior of US newspapers. Journal of Public Economics, 95(9), 1178-1189.

Levinson, J. D., Smith, R. J., \& Young, D. M. (2014). Devaluing death: An empirical study of implicit racial bias on jury-eligible citizens in six death penalty states. NYUL Rev, 89, 513.

Mauer, M. (2001). The causes and consequences of prison growth in the United States. Punishment \& Society, 3(1), 9-20.

Mc Gann, A., \& Sandholtz, W. (2012). Patterns of death penalty abolition, 1960-2005: Domestic and International Factors. International Studies Quarterly, 56(2), 275-289.

Mooney, C. Z., \& Lee, M. H. (2000). The influence of values on consensus and contentious morality policy: US death penalty reform, 1956-82. Journal of Politics, 62(1), 223-239.

Moraes, T. P. B. (2013). ¿ Por qué los hombres presentan un comportamiento más agresivo que las mujeres?: Por una antropología evelutiva del comportamiento agresivo. Nómadas Revista Critica de Ciencias Sociales y Juridicas, 37(1), 93-111.

Moraes, T. P. B. (2014). A discrepância quanto à frequência de comportamentos agressivos em homens e mulheres. Um estudo evolucionista sobre o comportamento agressivo em humanos. UNOPAR Científica Ciências Humanas e Educação, 15(1).

Moraes, T. P. B. (2015). Una mente punitiva: Un estudio sobre la relación entre interés por la punición y la pena de muerte en los Estados Unidos, rasgos de personalidad y preferencias sociales de 2004 a 2013. Tesis de doctorado, Universidad Argentina John Fitzgerald Kennedy.

Moraes, T. P. B., \& Torrecillas, G. L. S. (2014). Economia política pós-neoclássica: Uma crítica ao direito econômico, a teoria neoclássica e a política econômica. UNOPAR Científica Ciências Jurídicas e Empresariais, 14(2).

Moraes, T. P. B., \& Maia, S. P. A. (2014). Jornalismo na web e clonagem biológica: Um estudo sobre o tema clonagem nos cadernos de ciência online dos jornais O Estado de São Paulo e Folha de São Paulo. Aurora Revista de Arte, Mídia e Politica. 7(19), 71-96.

Moraes, T. P. B., \& Santos, R. M. (2015). Caza al terrorismo y corrida electoral: Un análisis sobre el impacto del interés regional por la muerte de Osama bin Laden y su relación 
con los votos en las elecciones presidenciales de 2012 en Estados Unidos. Revista PRISMA.COM, (27).

Moraes, T. P. B., Santos, R. M., \& Torrecillas, G. L. S. (2014). Qualidade democrática, percepção de corrupção e confiança política na América Latina. Revista Eletrônica de Ciência Politica, 5(1).

Pearson, A. (1998). Anti-terrorism and effective death penalty act of 1996: A return to guilt by association. The Wm Mitchell L Rev, 24, 1185.

Puglisi, R. (2011). Being The New York Times: The political behaviour of a newspaper. The BE Journal of Economic Analysis \& Policy, 11(1).

Rannik, J. K. (1996). The anti-terrorism and effective death penalty act of 1996: A death sentence for the 212 (c) Waiver. The University of Miami Inter-American Law Review, 123-150.

Ridout, T. N., \& Mellen, R. (2007). Does the media agenda reflect the candidates' agenda?. The Harvard International Journal of Press/Politics, 12(2), 44-62.

Sudbury, J. (2014). Global lockdown: Race, gender, and the prison-industrial complex. Routledge.

Usher, N. (2014). Making news at The New York Times. New Media World.

Windlesham, D. J. G. H. B., \& Windlesham, L. (1998). Politics, punishment, and populism. New York: Oxford University Press.

Zeisel, H., \& Gallup, A. M. (1989). Death penalty sentiment in the United States. Journal of Quantitative Criminology, 5(3), 285-296. 